\title{
Clinical Relevance of Cerebrospinal Fluid in Dogs (Review)
}

\author{
Cecilia-Gabriella DANCIU ${ }^{1 *}$, Ciprian Andrei OBER², Liviu OANĂ², Laurenț OGNEAN ${ }^{1}$ \\ ${ }^{1}$ Department of Physiology, University of Agricultural Science and Veterinary Medicine Cluj-Napoca, \\ Romania \\ ${ }^{2}$ Department of Surgery, University of Agricultural Science and Veterinary Medicine Cluj-Napoca, \\ Romania \\ *corresponding author: cecilia_danciu@yahoo.com
}

Bulletin UASVM Veterinary Medicine 76(2)/2019

Print ISSN 1843-5270; Electronic ISSN 1843-5378

doi:10.15835/buasvmcn-vm:2018.0038

\begin{abstract}
:
From the early $20^{\text {th }}$ century, the cerebrospinal fluid (CSF) analysis was an invaluable diagnostic process in clinical neurology and later in veterinary neurology. For the clinicians, the CSF analysis provides reliable information about the neurological health and the presence of a disease.

The purpose of this review is to bring scientific evidence and support for the current state regarding the clinical relevance of cerebrospinal fluid analysis in veterinary neurology. The utility of this review is to highlight the canine breed specific diseases in veterinary neurology and the role of CSF analysis for the diagnosis of CSF inflammatory disorders.

The analysis of cerebrospinal fluid represents an important diagnostic tool, which has to be assessed in every neurological patient in order to obtain information about the central nervous system. Moreover, we strongly encourage to step forward with this diagnostic procedure and corroborate with the diagnostic imaging results.
\end{abstract}

Keywords: Cerebrospinal fluid, inflammation, cytology, dog

\section{Introduction}

Cerebrospinal Fluid (CSF) is an ultra-filtrate of plasma that is produced by the choroid plexus within the ventricular system to the central canal of the spinal cord. CSF has multiple roles in the central nervous system, such as physical support, pressure modulation, metabolites, nutrients, neurotransmitters transport and maintains also the ionic balance (Di Terlizzi and Platt, 2009).

Changes in the central nervous system can cause changes in the functionality and composition of the CSF to a greater or lesser degree. This is why CSF became an integral part of the neurological investigation. For veterinary practitioners information about the CSF can lead to neurological disorders, such as inflammatory, degenerative or neoplastic (De Lahunta, 1977; Vandevelde and Spano, 1977).

To obtain CSF from a patient, there are specific collection sites, such as cerebellomedullary cistern and from the lumbar subarachnoid space. Details of the CSF collection techniques were not the objective of this review and are found elsewhere (Jamison and Lumsden, 1988).

After the collection, the cerebrospinal fluid analysis should be done within 30 minutes for an 
accurate cell count and cytology (Chrisman, 1992). The CSF white blood cell (WBC) count is one major part of the analysis. Normal values are considered 5 cells $/ \mu \mathrm{L}$.

Elevated CSF WBC count is called pleocytosis and usually, it is associated with inflammation of the central nervous system (CNS). CSF cytology is necessary at every CSF evaluation, even if the WBC is low (Christopher et al., 1988). Another parameter routinely evaluated on CSF is the total protein. Normal protein levels may be 10 to $25 \mathrm{mg} /$ $\mathrm{dL}$ in the CSF, compared to normal serum level 5 to $7.5 \mathrm{~g} / \mathrm{dL}$ (Jamison and Lumsden, 1988). Elevation of CSF protein level may appear in diseases that alter the BBB, local necrosis, interruption of the CSF flow or intrathecal globulin production (Sorjonen, 1990).

\section{Inflammatory disorders affecting the canine CNS}

Inflammatory diseases of the CNS in dogs with forebrain neurological signs are important diagnostic considerations. A variety of inflammatory conditions of the CNS can cause CSF changes. Inflammatory conditions can be divided into infectious etiology (such as bacterial, canine distemper virus, rabies, cryptococcosis, toxoplasmosis, and neosporosis infection) and noninfectious. Meningoencephalomyelitis termed also meningoencephalomyelitis of unknown origin, has several subtypes: steroid responsive meningitis - arteritis, eosinophilic meningoencephalitis, granulomatous meningoencephalo-myelitis (GME) and necrotizing encephalitis (with two subtypes: Necrotizing meningoencephalomyelitis (NME) and necrotizing leucoencephalitis) (Cornelis et al., 2019). All have a common pathological characteristic described, influx of leukocytes into the brain, spinal cord or meninges. In the inflammatory process more than one structure can be involved, for instance inflammation of the brain and meninges together (William, 1998).

A usual misconception among veterinarians is that dogs with inflammatory CNS disease are usually with systemic manifestations also but commonly have no extraneural signs. Moreover, the neurological deficits are not disease-specific, because the inflammatory process can affect any portion of the CNS and can develop a variety of neurological signs (Tipold, 1995). A retrospective study on diagnosis of inflammatory and infectious diseases of the CNS in dogs shows that generalized or focal seizures are common findings and are seen in $13 \%$ of dogs with inflammatory disease of the CNS (Tipold, 1995). Other clinical signs manifested in inflammatory disorders localized in the CNS are central vestibular dysfunction, hypermetria or disorders of consciousness (Nelson and Couto, 2014).

A retrospective study of Radaelli and Platt (2002) about bacterial meningoencephalomyelitis in dogs demonstrated that it is an uncommon disease, but should be considered when an animal is presented with CNS signs, acute neck pain, and pyrexia. Furthermore, the neurological signs, neck pain, and pyrexia with abnormal complete blood count and serum chemistry profiles were shown to be useful to indicate an infection localized in CNS. In the same study, CSF was analyzed in 14 dogs and the CSF was abnormal in $93 \%$ of samples. All of them had abnormal CSF protein level (range: 164-777.7 mg/dL; mean: $337.0 \mathrm{mg} / \mathrm{dL}$; reference range: $15.0-35.0 \mathrm{mg} / \mathrm{dL}$ ) and 11 of 13 dogs had increased WBC cell count (range: 18-10,850 cell/ $\mu \mathrm{L}$ ), with a prevalence of neutrophils in 9 of the 13 dogs, monocytes in 2 of the 13 dogs, lymphocytes and eosinophils in 1 of 13 dogs. The CSF was also cultured in 8 of 14 dogs. The results of the culture of CSF in 8 dogs were positive in only $1(13 \%)$ sample (Corynebacterium spp) (Radaelli and Platt, 2002).

Canine distemper virus has various neuropathological presentations; under natural condition, acute to chronic demyelinating encephalomyelitis is the most widespread clinical forms. Neurological manifestations usually begin after 1 to 3 weeks after recovery from the initial systemic illness and may involve disorientation, seizures and circling. Moreover, "chewing gum" seizures produced by polioencephalomalacia of temporal lobes are frequently described. Additional "distemper chorea" is very common in dogs with distemper encephalomyelitis (Greene and Appel, 2006).

Related to cryptococcosis, in a large case series from 195 patients (dogs and cats) thirty percent of the dogs had CNS and/or disseminated signs. This study shows that cats are five times more prone to develop cryptococcosis than dogs (O'Brien et al., 2004).

Protozoa is nota common cause of neurological diseases in canine (Thomas, 1998), however, Toxo- 
plasma gondii and Neospora caninum (Paixão and Santos, 2004) are occasionally reported. Based on a study, many animals are serologically positive for toxoplasmosis, although few develop clinical manifestations of the disease (Dubey and Lappin, 2012). However, studies shown that the most common clinical signs of CNS in toxoplasmosis were ataxia, seizure, tremor, cranial nerve disorders, progressive paresis and paralysis (Averill and De Lahunta, 1971; Nesbit et al., 1981; Suter et al., 1984; Braund et al., 1988; Davidson, 2000).

In a recent report in which Neospora caninum and Erlichia canis co-infection with meningoencephalitis was described (Aroch et al., 2018), CSF obtained from cisterna magna showed a marked pleocytosis, the total nucleated cell count was $650 \mathrm{cell} / \mu \mathrm{L}$ and increase protein concentration was observed $(791,3 \mathrm{mg} / \mathrm{dL})$. CSF cytology showed a mixed pleocytosis with $44 \%$, eosinophils, $34 \%$ monocytes, $14 \%$ neutrophils, $6 \%$ lymphocytes and 2\% reactive macrophages (Aroch et al., 2018). CSF cytology may reveal bacteria or fungal elements, further CSF culture can solution the definitive diagnosis (Chrisman, 1992). Meningoencephalomyelitis of unknown origin (MUO) enclose the idiopathic CNS diseases (Talarico and Schatzberg, 2010). This group of diseases has a worldwide distribution and was reported for $5 \%$ to $25 \%$ of all CNS disorders in canine patients (Cuddon and Smith-Maxie, 1984). An anti-astrocyte autoantibody was recently identified in the cerebrospinal fluid of dogs with GME or NME, indicating a possible relationship between these two diseases and the autoantibody (Matsuki et al., 2004). Clinical signs secondary to MUO may be acute or chronic and can result in focal or multifocal lesions. In recent studies, Pugs, Maltese and Chihuahuas were considered to have a possible genetic predisposition for developing MUO (Schrauwen et al., 2014; Barber et al., 2012). GME may have a mild to moderate CSF lymphocytic pleocytosis (Bailey and Higgins, 1986b). Other study described the cytological aspects of pleocytosis associated with GME, in which the predominant cells are mononuclear, including small lymphocytes (60\% to $90 \%)$, monocytes (10\% to $20 \%$ ) and large macrophages (Braund, 2005 ). Neutrophils usually are $1 \%$ to $20 \%$ of the cell population; but occasionally they can be the predominant cell type, accounting from up to
$50 \%-60 \%$ of the cell type (Braund, 2005; Munana and Luttgen, 1988; Bailey and Higgins, 1986a). According to Braund (2005) in dogs with GME, the total nucleated cell count usually ranges from 50 to $900 \mathrm{cell} / \mu \mathrm{L}$, varying from 0 to $11,840 \mathrm{cell} / \mu \mathrm{l}$. Thomas and Eger (1989) showed that about 10\% of dogs with GME had normal cell count values.

In another study (Lamb et al., 2005) the authors described the signs that may be associated with meningoencephalitis on magnetic resonance imaging (MRI). Twenty-five dogs with inflammatory CSF were included, $76 \%$ of them showing MRI abnormalities. Although as shown above, several diagnostic techniques were employed for the diagnosis of MUO a definitive diagnosis can only be made by histopathological examination (Uchida et al., 2016).

In order to reach a diagnosis, the infectious diseases of the CNS should be commonly ruled out by serum/CSF titers and polymerase chain reaction testing, although studies demonstrated that infectious etiologies are uncommon causes of inflammatory disease in the USA and Europe (Schatzberg et al.,2005; Barber et al., 2012). MRI and CSF analysis are also important diagnostic tools and could be considered for the definitive diagnosis (Smith et al., 2009).

\section{Degenerative and neoplastic disorders on canine CSF}

In CNS neoplastic disorders CSF analysis is frequently nonspecific, but occasionally, if neoplastic cells are exfoliated as may occur in lymphoma, CSF analysis could confirm the diagnosis (Meinkoth and Crystal, 1999; Freeman and Raskin, 2001; Baker and Lumsden, 2000). More frequently, CSF analysis may help to distinguish the inflammatory or neoplastic nature of a mass seen on MRI (Bohn et al., 2006). In canine primary intracranial neoplasia, CSF inflammatory changes can be consistent with albumino-cytological dissociation (Bagley et al., 1999). Elevated nucleated cell counts are caused not only by primary CNS inflammation, but also in secondary inflammatory responses to trauma, neoplasia, infarction, haemorrhage related with intervertebral disc disease (IVDD) and fibrocartilaginous embolism (total nucleated cell count 6-1200 cells/ $\mu \mathrm{L}$ ) (Meinkoth and Crystal, 1999; Bagley and Bohn, 2003; Lamb et al., 2005). It has been recommended that CSF analysis is avoidable 
in those cases in which MRI findings is strongly suggesting of IVDD (Bohn et al., 2006), although CSF pleocytosis is positively associated with the severity of the spinal cord injury in IVDD. Moreover, the percentage of macrophages can be used as a prognosticating value for dogs with IVDD and loss of deep pain sensation (Srugo et al., 2011).

\section{Conclusion}

Central nervous system inflammation is an important disorder to be considered when a dog is presented with a history of abnormal behaviour, vestibular signs or seizures. Cerebrospinal fluid analysis is an ancillary diagnostic test that can give important information about the types of CNS inflammation and provide a differential diagnosis. Additional diagnostic tests as advanced clinical imaging and molecular biology can further corroborate the information obtained by CSF analysis and provide more accurate clinical diagnosis. Despite its clinical usefulness, the information obtained by cerebrospinal fluid analysis should be interpreted as a preliminary diagnostic. Furthermore, new biomarkers which can improve the clinical diagnosis of neurological diseases need to be introduced and tested also in veterinary medicine.

Acknowledgments. This research did not receive any specific grant from funding agencies in the public, commercial, or not-for-profit sectors.

\section{References}

1. Aroch I, Baneth G, Salant H, Nachum-Biala Y, Berkowitz A, Shamir M, Chai O (2018). Neospora caninum and Erlichia canis co-infection in a dog with meningoencephalitis. Vet ClinPathol, 47:289-293.

2. Averill DR, De Lahunta A (1971). Toxoplasmosis of the canine nervous system: Clinicopathological findings in four cases. Journal of the American Veterinary Medical Association, 159:1134-1141.

3. Bagley RS, Bohn AA (2003). Interpreting the results of CSF analysis in dogs and cats. Veterinary Medicine, 98:499506.

4. Bagley RS, Gavin PR, Moore MP (1999). Clinical signs associated with brain tumors in dogs: 97 cases (19921997). J Am Vet Med Assoc, 215:818-819.

5. Bailey C, Higgins R (1986a). Characteristic of cisternal cerebrospinal fluid associated with primary brain tumors in the dog: A retrospective study. JAVMA,188(4):414-417.

6. Bailey CS, Higgins RJ (1986b). Characteristic of cerebrospinal fluid associated with canine granulomatous meningoencephalomyelitis: A retrospective study. JAVMA,188:418-42.
7. Baker R, Lumsden JH (2000). Cerebrospinal fluid. In R. Baker, \& J.H. Lumsden (Eds.), Color Atlas of Cytology of the Dog and Cat (pp. 95-115). St. Louis, MO: The CV Mosby Co.

8. Barber RM, Porter BF, Li Q, May M, Claiborne MK, Allison AB (2012). Broadly reactive polymerase chain reaction for pathogen detection in canine granulomatous meningoencephalomyelitis and necrotizing meningoencephalitis. Journal of Veterinary Internal Medicine, 26:962-968.

9. Bohn AA, Wills TB, West CL (2006). Cerebrospinal fluid analysis and magnetic resonance imaging in the diagnosis of neurologic disease in dogs: A retrospective study. Vet ClinPathol, 35:315-320.

10. Braund K (2005). Granulomatous meningoencephalomyelitis In C. Vite (Eds.), Clinical Neurology in Small Animals Localization, Diagnosis and Treatment. Ithaca, NY: International Veterinary Information Service.

11. Braund KG, Blagburn BL, Toivio-Kinnucan M, Amling KA, Pidgeon GL (1988). Toxoplasma polymyositis/ polyneuropathy - a new clinical variant in two mature dogs. Journal of the American Animal Hospital Association, 24(1): 93-97.

12. Chrisman CL (1992). Cerebrospinal fluid analysis. VetClin North Am Small AnimPract,22: 781-810.

13. Christopher MM, Perman V, Hardy RM (1988). Reassessment of cytologic values in canine cerebrospinal fluid by use of cytocentrifugation. J Am Vet Med Assoc, 192: 1726.

14. Cornelis I, Van Ham L, Gielen I, De Decker S, Bhatti SFM (2019). Clinical presentation, diagnotis findings, prognostic factors, treatment and outcome in dogs with meningoencephalomyelitis of unknown origin: A review. The veterinary Journal, 244: 37-44.

15. Cuddon PA, Smith-Maxie L (1984). Reticulosis of the central nervous system in the dog. CompendContinEducPract Vet,6: 23-32.

16. Davidson MG (2000). Toxoplasmosis. Veterinary Clinics of North America Small Animal Practice, 30(5): 1051-1062.

17. De Lahunta A (1977). Cerebrospinal fluid and hydrocephalus In Veterinary Neuroanatomy and Clinical Neurology (pp. 33). Philadelphia: WB Saunders.

18. Di Terlizzi R, Platt SR (2009). The function, composition and analysis of cerebrospinal fluid in companion animals: Part II - Analysis. Vet J. 180(1): 15-32.

19. Dubey JP, Lappin MR (2012). Toxoplasmosis and Neosporosis. InC.E. Greene (Eds.) Infectious Diseases of the Dog and Cat. 4th ed. (pp. 806-827). Saint Louis: Elsevier.

20. Freeman KP, Raskin RE (2001) Cytology of the central nervous system. In R.E. Raskin, \& D.J. Meyer (Eds.), Atlas of Canine and Feline Cytology (pp: 325-365). Philadelphia, PA: WB Saunders.

21. Greene CE, Appel MJ (2006). Canine distemper. In C.E. Greene (Eds.), Infectious diseases of the dog and cat (pp.25-41). St Louis: Elsevier.

22. Jamison EM, Lumsden, JH (1988). Cerebrospinal fluid analysis in the dog: methodology and interpretation. 
In Seminars in veterinary medicine and surgery (small animal), 3:2, 122.

23. Lamb CR, Croson PJ, Capello R, Cherubini GB (2005). Magnetic resonance findings in 25 dogs with inflammatory cerebrospinal fluid. Veterinary Radiology \& Ultrasound, 46 (1): 17-22.

24. Matsuki N, Fujiwara K, Tamahara S (2004). Prevalence of autoantibodies in cerebrospinal fluids from dogs with various CNS diseases. J Vet Med Sci, 66: 295-297.

25. Meinkoth JH, Crystal MA (1999). Cerebrospinal fluid analysis. In R.L. Cowell, R.D. Tyler, \& J. H. Meinkoth (Eds.), Diagnostic Cytology and Hematology of the Dog and Cat. ( $2^{\text {nd }}$ ed.) pp. 125-141). St. Louis, MO: Mosby.

26. Munana KR, Luttgen PJ (1988). Prognostic factors for dogs with granulomatous meningoencephalomyelitis: 42 cases (1982-1996). JAVMA, 212: 1902-1906.

27. Nelson RW, Couto CG (2014). Small animal internal medicine. ( $5^{\text {th }}$ ed.). St. Louis: Elsevier, (Chapter 66).

28. Nesbit JW, Lourens DC, Williams MC (1981). Spastic paresis in two littermate pups caused by Toxoplasma gondii. Journal of the South African Veterinary Association, 52: 243-246.

29. O'Brien CR, Krockenberger MB, Wigney DI, Martin P, Malik R (2004). Retrospective study of feline and canine cryptococcosis in Australia from 1981 to 2001:195 cases. Medical Mycology, 42: 449-460.

30. Paixão TA, Santos RL (2004). Encefalite por Neospora caninum e Toxoplasma gondi iem cães. ClínicaVeterinária, 9(48): 44-52.

31. Radaelli ST, Platt SR (2002). Bacterial Meningoencephalomyelitis in Dogs: A Retrospective Study of 23 Cases (1990-1999). J Vet Intern Med, 16: 159-163.

32. Schatzberg SJ, Haley NJ, Barr SC, De Lahunta A, Sharp NJ (2005) Polymerase chain reaction screening for DNA viruses in paraffin-embedded brains from dogs with necrotizing meningoencephalitis, necrotizing leukoencephalitis, and granulomatous meningoencephalitis. Journal of Veterinary Internal Medicine 19: 553-559.

33. Schrauwen I, Barber RM, Schatzberg SJ, Siniard AL, Corneveaux JJ, Porter BF, Vernau KM, Keesler RI, Matiasek K, Flegel T, Miller AD, Southard T, Mariani CL, Johnson GC, Huentelman MJ (2014). Identification of novel genetic risk loci in maltese dogs with necrotizing meningoencephalitis and evidence of a shared genetic risk across toy dog breeds. PLoS One, 9:11. Doi: 10.1371/ journal.pone.0112755.

34. Smith PM, Stalin CE, Shaw D, Granger N, Jeffery ND (2009). Comparison of two regimens for the treatment of meningoencephalomyelitis of unknown etiology. Journal of Veterinary Internal Medicine, 23: 520-526.

35. Sorjonen DC (1990). Clinical and histopathological features of granulomatous meningoencephalomyelitis in dogs. JAAHA, 26: 141-147.

36. Srugo I, Aroch I, Christopher MM, Chai O, Goralnik L, Bdolah-Abram T, Shamir MH (2011). Association of Cerebrospinal Fluid Analysis Findings with Clinical Signs and Outcome in Acute Nonambulatory Thoracolumbar Disc Disease in Dogs, J Vet Med, 25: 846-855.

37. Suter MM, Hauser B, Palmer DG, Oettli P (1984). Polymyositis - polyradiculitis due to toxoplasmosis in the dog: Serology and tissue biopsy as diagnostic aids. ZentralblattfuerVeterinaermedizin, 31(10): 792- 798.

38. Talarico LR, Schatzberg SJ (2010). Idiopathic granulomatous and necrotising inflammatory disorders of the canine central nervous system: a review and future perspectives. J. Small AnimPract, 51: 138-149.

39. Thomas JB, Eger C (1989). Granulomatous meningoencephalomyelitis in 21 dogs, Journal of Small Animal Practice, 30 (5): 287-293.

40. Thomas WB, (1998). Inflammatory diseases of the central nervous system in dogs. Clinical Techniques in Small Animal Practice, 13(3):167-178.

41. Tipold A (1995). Diagnosis of inflammatory and infectious diseases of the central nervous system in dogs: a retrospective study. J Vet Int Med, 9: 304-314.

42. Uchida K, Park E, Tsuboi M, Chambers JK, Nakayama H (2016). Pathological and immunological features of canine necrotizing meningoencephalitis and granulomatous meningoencephalitis. Vet J, 213: 72-77.

43. Vandevelde M, Spano JS (1977). Cerebrospinal fluid cytology in canine neurologic disease. Am J Vet Res, 38: 1827-1832.

44. William BT (1998). Inflammatory Diseases of the central nervous system in dogs. Clinical Techniques in Small Animal Practice, 13(3): 167-168. 